\title{
25 Research Soure \\ Relationship Between Overweight and Obesity and Cardiac Dimensions and Function in a Paediatric Population.
}

Juan Fernández Cabeza ( $\sim$ juanfca988@gmail.com )

Hospital Universitario Reina Sofía: Hospital Universitario Reina Sofia https://orcid.org/0000-00017615-0724

Cristhian H Aristizábal-Duque

Hospital Universitario Reina Sofía: Hospital Universitario Reina Sofia

Isabel María Blancas Sánchez

Hospital Universitario Reina Sofía: Hospital Universitario Reina Sofia

Martín Ruíz Ortiz

Hospital Universitario Reina Sofía: Hospital Universitario Reina Sofia

\section{Ana Rodríguez Almodóvar}

Hospital Universitario Reina Sofía: Hospital Universitario Reina Sofia

\section{Mónica Delgado Ortega}

Hospital Universitario Reina Sofía: Hospital Universitario Reina Sofia

Fátima Esteban Martínez

Hospital Reina Sofía: Hospital Reina Sofia

Manuel Romero Saldaña

Universidad de Córdoba Facultad de Medicina: Universidad de Cordoba Facultad de Medicina y

Enfermeria

Francisco Javier Fonseca del Pozo

Hospital Universitario Reina Sofía: Hospital Universitario Reina Sofia

Manuel Pan Álvarez-Ossorio

Hospital Universitario Reina Sofía: Hospital Universitario Reina Sofia

María Dolores Mesa Rubio

Hospital Universitario Reina Sofía: Hospital Universitario Reina Sofia

\section{Research Article}

Keywords: Childhood obesity, Echocardiography, Left ventricular ejection fraction, Left ventricular mass

Posted Date: September 24th, 2021

DOl: https://doi.org/10.21203/rs.3.rs-921234/v1 
License: (c) (i) This work is licensed under a Creative Commons Attribution 4.0 International License. Read Full License

Version of Record: A version of this preprint was published at European Journal of Pediatrics on January 25th, 2022. See the published version at https://doi.org/10.1007/s00431-022-04384-0. 


\section{Abstract}

Obesity in adults is associated with left ventricular hypertrophy, dilatation and myocardial fibrosis, as well as heart failure and coronary heart disease. These associations have been studied to a lesser extent in the paediatric population. This study aims to investigate the relationship between obesity and cardiac structure and function in the paediatric population. In a southern Spanish town, we selected all inhabitants aged 6-17 years stratifying by age, gender, and educational centres. We performed a complete transthoracic echocardiogram evaluating all the cardiac morphological and functional parameters commonly measured in an echocardiographic study. There were 212 children and adolescents included. Of them, 48,1\% were males. The mean age was $10.9 \pm 3.0$ years. $106(50 \%)$ were normal weight, $57(26.9 \%)$ overweight and $49(23.1 \%)$ obese. Sex and age were similar in all three groups. Overweight and obesity were associated with larger left ventricular end-diastolic and end-systolic volumes $(p<0.0005)$, greater left ventricular mass $(p<0.0005)$ and smaller ejection fraction $(p<0.0005)$. They were also associated with larger atrial, aortic and right ventricular size. Lateral and mean E/e' ratios were higher ( $p=0.007$ and $p=0.01$ respectively). Body mass index was independently associated with all cavity size variables as well as left ventricular ejection fraction.

Conclusion: Childhood obesity is independently associated with larger heart chambers, greater left ventricle mass, and smaller left ventricle ejection fraction.

\section{Introduction}

Childhood obesity is one of the most significant public health issues of the 21 st century. In Spain, the prevalence of overweight and obesity in the paediatric population is $34.1 \%$ and $10.3 \%$ respectively [1]. This prevalence is increasing at an alarming rate: childhood overweight and obesity is estimated to have increased globally by $47.1 \%$ over the past three decades [2].

Overweight and obesity are associated with the development of cardiovascular risk factors in the paediatric age group, such as hypertension, dyslipidaemia, hyperinsulinemia and chronic inflammation [3]. Childhood obesity has also been linked to the development of cardiovascular risk factors in adulthood and thus to increased morbidity and mortality $[4,5]$.

Obesity in adulthood has been identified as a causative agent of cardiovascular disease independently of other classical risk factors. Obesity-related clinical entities include the development of coronary heart disease, heart failure, atrial fibrillation and sudden death [6].

At the cardiac level, in adult obesity there is an increase in cardiac output because of the body's increased metabolic demands. This haemodynamic alteration secondary to obesity has been linked to left ventricular (LV) dilatation and hypertrophy, as well as to the development of obesity-related cardiomyopathy. This pathological entity involves an increase in ventricular mass and dilatation of the cardiac chambers, as well as myocyte hypertrophy and the development of myocardial fibrosis. The 
presence of diastolic dysfunction related to this cardiomyopathy accounts for $50 \%$ of cases of heart failure in this group $[7,8,9,10]$.

In childhood, the relationship between overweight and obesity with cardiac morphological and functional alterations it's not completely defined. There are few studies relating overweight and obesity to cardiac geometry and function, although LV enlargement and alterations in diastolic function have been reported in childhood obesity $[11,12,13]$.

The aim of our study is to research the relationship between the overweight and obesity with changes in cardiac structure and function in a paediatric population in our environment.

\section{Methods}

We carried out a cross-sectional study, selecting a consecutive sample of 265 primary and secondary school children and adolescents from a town of around 3000 inhabitants in Andalusia. The sample was stratified by age, gender, and educational centres. Healthy children and adolescents aged 6-17 years who accepted and signed consent by their parents or legal guardians were included. Those who were outside the age range, had previously known acquired or congenital cardiac pathology, or did not give consent were excluded. Likewise, those who presented cardiac pathology in the echocardiography study.

The anthropometric data of the children and adolescents were collected using standardised measurements of weight and height. As for the definition of childhood obesity, there is no agreed criterion for establishing overweight and obesity based on body mass index (BMI). In this study, the definition proposed by the World Health Organisation was used: overweight was defined for sex-and age-specific $\mathrm{BMI}$ values greater than one standard deviation and less than two standard deviations; and obesity was defined for sex-and age-specific BMI values greater than two standard deviations [14]. Blood pressure was measured, and blood biochemistry was performed to determine fasting basal glycaemia and lipid profile.

Each subject underwent a standard transthoracic echocardiographic study with a Philips iE33 and an S51 probe (Philips Medical Systems, Amsterdam, The Netherlands). All images were recorded and saved for posterior digital analysis. Parasternal long-axis M-mode images were obtained to measure left ventricular (LV) diastolic and systolic diameter, interventricular septal thickness, LV posterior wall thickness and aortic size. Calculation of LV mass was performed by the Devereux formula [15]: $0.8 \times\{1.04$ [(LVDD + PW + IVS $\left.\left.)^{3}-(\text { LVDD })^{3}\right]\right\}+0.6$; with LVDD corresponding to LV diastolic diameter, $\mathrm{PW}$ to posterior wall thickness and IVS to interventricular septal thickness.

Two-, three- and four-chamber images were obtained through the apical window. The end-diastolic and end-systolic volumes were obtained using Simpson's method, and the left ventricular ejection fraction (LVEF) value was calculated from them. The basal diameter of the right ventricle was measured in the apical four-chamber plane focused on the right ventricle. Left atrial volume was calculated by the Simpson biplane method. Right atrial area was obtained by apical four-chamber planimetry. 
By pulsed Doppler, LV diastolic function was analysed through mitral filling flow, placing the sample volume at the level of the free edges of the mitral leaflets in the apical four-chamber plane. E-wave and Awave were measured, and the E/A ratio was calculated. By tissular Doppler, lateral and medial e' waves were measured; and average e' wave and lateral, medial and average $\mathrm{E} / \mathrm{e}^{\prime}$ ratios were calculated according to previous measurements. With continuous Doppler through the tricuspid valve in apical four chambers, the pressure gradient from the right ventricle to the right atrium was calculated by means of the maximum tricuspid regurgitation velocity.

All measurements were performed in accordance with current recommendations for echocardiography in the paediatric population [16].

For the descriptive analysis, quantitative variables are represented by their mean and standard deviation and qualitative variables by frequency and percentage. The Kolmogoroff-Smirnoff test was used to check which variables followed a normal distribution. For the comparison of subgroups, we used the ANOVA test for quantitative variables and the chi-square test for qualitative variables. Univariate regression analysis was performed to assess the relationship of BMI with the different echocardiographic parameters. Multiple regression analysis was performed to assess the independent influence of BMI on echocardiographic parameters, after adjusting for other baseline covariates. SPSS v 21.0 (SPSS Inc., Chicago, USA) was used for the analysis. A $p<0.05$ value was considered significant.

\section{Results}

A total of 265 children and adolescents were initially selected, the final resulting sample was 212 , after 53 subjects were excluded: 26 cases did not give consent, 4 cases did not meet age criteria, 8 cases presented cardiac pathologies in the echocardiographic study, 14 cases showed unacceptable quality or other technical problems in the echocardiographic study and in one case the anthropometric variables were missing.

Of the 212 children and adolescents, 106 (50.0\%) were normal weight, 57 (26.9\%) were overweight and 49 $(23.1 \%)$ were obese. The mean age was $10.9 \pm 3.0$ years and $48.1 \%$ were boys. The main clinical characteristics of the different groups are shown in Table 1. Gender and age were similar in the three groups. Statistically significant differences were found in anthropometric parameters (weight, height, and body mass index), blood pressure, blood glucose, HDL, LDL and triglyceridaemia, with higher values in the overweight and obese groups for all parameters except HDL. 
Table 1

Clinical characteristics.

\begin{tabular}{|c|c|c|c|c|c|}
\hline & Total & $\begin{array}{l}\text { Normal } \\
\text { weight }\end{array}$ & Overweight & Obesity & $\mathbf{p}$ \\
\hline Age (years) & $10,9 \pm 3,0$ & $10,9 \pm 3,2$ & $10,7 \pm 2,7$ & $11,0 \pm 2,8$ & 0,8 \\
\hline Sex (\% male) & $\begin{array}{l}102 \\
(48,1 \%)\end{array}$ & $52(49,1 \%)$ & $29(50,9 \%)$ & $21(42,9 \%)$ & 0,7 \\
\hline Weight (kg) & $43,4 \pm 17,2$ & $35,7 \pm 12,8$ & $44,3 \pm 13,3$ & $59,2 \pm 18,4$ & $<0,0005$ \\
\hline Height (cm) & $\begin{array}{l}143,2 \pm \\
16,2\end{array}$ & $141,0 \pm 17,2$ & $\begin{array}{l}143,3 \pm \\
15,2\end{array}$ & $\begin{array}{l}148,0 \pm \\
14,9\end{array}$ & 0,046 \\
\hline $\mathrm{BMI}\left(\mathrm{kg} / \mathrm{m}^{2}\right)$ & $20,3 \pm 4,4$ & $17,3 \pm 2,2$ & $20,9 \pm 2,4$ & $26,2 \pm 3,6$ & $<0,0005$ \\
\hline CSA (Dubois formula) $\left(\mathrm{m}^{2}\right)$ & $1,3 \pm 0,3$ & $1,2 \pm 0,3$ & $1,3 \pm 0,3$ & $1,5 \pm 0,3$ & $<0,0005$ \\
\hline $\mathrm{SBP}(\mathrm{mmHg})$ & $\begin{array}{l}110,0 \pm \\
11,0\end{array}$ & $106,9 \pm 10,5$ & $\begin{array}{l}111,6 \pm \\
10,2\end{array}$ & $\begin{array}{l}114,6 \pm \\
10,7\end{array}$ & $<0,0005$ \\
\hline $\mathrm{DBP}(\mathrm{mmHg})$ & $68,2 \pm 6,5$ & $67,1 \pm 5,9$ & $68,7 \pm 6,5$ & $69,9 \pm 7,2$ & 0,03 \\
\hline $\begin{array}{l}\text { Blood glucose level } \\
\text { (mg/dL) }\end{array}$ & $75,9, \pm 6,8$ & $74,7 \pm 6,6$ & $75,7 \pm 5,7$ & $78,5 \pm 8,0$ & 0,005 \\
\hline HbA1c (\%) & $5,3 \pm 0,3$ & $5,3 \pm 0,3$ & $5,3 \pm 0,3$ & $5,4 \pm 0,3$ & 0,2 \\
\hline Total Cholesterol (mg/dL) & $\begin{array}{l}167,1 \pm \\
29,8\end{array}$ & $162,7 \pm 26,7$ & $\begin{array}{l}170,6 \pm \\
37,0\end{array}$ & $\begin{array}{l}172,7 \pm \\
25,4\end{array}$ & 0,09 \\
\hline $\mathrm{HDL}(\mathrm{mg} / \mathrm{dL})$ & $57,0 \pm 12,8$ & $59,4 \pm 12,6$ & $57,7 \pm 11,3$ & $51,1 \pm 13,2$ & 0,001 \\
\hline $\mathrm{LDL}(\mathrm{mg} / \mathrm{dL})$ & $94,9 \pm 24,0$ & $89,2 \pm 21,5$ & $\begin{array}{l}100,8 \pm \\
25,7\end{array}$ & $\begin{array}{l}100,7 \pm \\
24,3\end{array}$ & 0,002 \\
\hline Triglycerides (mg/dL) & $73,1 \pm 41,0$ & $66,5 \pm 31,1$ & $71,2 \pm 28,1$ & $89,8 \pm 63,2$ & 0,004 \\
\hline
\end{tabular}

Table 2 shows the comparison of echocardiographic structural variables and LVEF in the three groups.

For both the LV size and LV thickness variables, the overweight group had higher values than the normal weight group, and the obese group had higher values than the overweight group. Comparisons of diastolic diameter $(p=0.003)$, end-diastolic volume $(p<0.0005)$, end-systolic volume $(p<0.0005)$, interventricular septum size $(p=0.01)$, posterior wall $(p<0.0005)$ and LV mass $(p<0.0005)$ were statistically significant. Left atrial volume $(p=0.004)$, right atrial area $(p=0.001)$, basal diameter and right ventricular outflow tract $(p=0.001$ and $p<0.0005$ respectively $)$ and aortic size $(p<0.0005)$ behaved in the same way. LVEF was significantly lower in the obese group than in the overweight group, and 
significantly lower in the overweight group than in the normal weight group $(p<0.0005)$, with no significant post hoc comparison of the overweight and obese groups. 
Table 2

Echocardiographic structural characteristics and LVEF.

\begin{tabular}{|c|c|c|c|c|c|c|c|c|}
\hline & Total & $\begin{array}{l}\text { Normal } \\
\text { Weight }\end{array}$ & Overweight & Obesity & p & $\mathrm{p}^{\mathrm{a}}$ & $p^{b}$ & $p^{c}$ \\
\hline LVDD (mm) & $\begin{array}{l}42,2 \pm \\
5,6\end{array}$ & $41,1 \pm 5,5$ & $42,8 \pm 5,4$ & $\begin{array}{l}44,2 \pm \\
5,5\end{array}$ & 0,003 & 0,1 & 0,003 & 0,4 \\
\hline LVSD (mm) & $\begin{array}{l}26,0 \pm \\
4,8\end{array}$ & $25,3 \pm 4,7$ & $26,1 \pm 4,9$ & $\begin{array}{l}27,2 \pm \\
4,8\end{array}$ & 0,07 & 0,6 & 0,06 & 0,4 \\
\hline IVS (mm) & $\begin{array}{l}6,6 \pm \\
1,5\end{array}$ & $6,3 \pm 1,4$ & $6,9 \pm 1,3$ & $\begin{array}{l}7,0 \pm \\
1,7\end{array}$ & 0,01 & 0,2 & 0,03 & 0,5 \\
\hline PW (mm) & $\begin{array}{l}6,0 \pm \\
1,5\end{array}$ & $5,6 \pm 1,4$ & $6,1 \pm 1,3$ & $\begin{array}{l}6,8 \pm \\
1,6\end{array}$ & $\begin{array}{l}<, 0005 \\
0,00\end{array}$ & 0,03 & $\begin{array}{l}<, 0005 \\
0,00\end{array}$ & 0,05 \\
\hline LV mass (g) & $\begin{array}{l}78,3 \pm \\
33,2\end{array}$ & $\begin{array}{l}69,3 \pm \\
30,1\end{array}$ & $80,9 \pm 30,2$ & $\begin{array}{l}94,8 \pm \\
36,5\end{array}$ & $\begin{array}{l}<, 0005 \\
0,00\end{array}$ & 0,05 & $\begin{array}{l}<, 0005 \\
0,000\end{array}$ & 0,09 \\
\hline LVEDV (mL) & $\begin{array}{l}64,1 \pm \\
20,9\end{array}$ & $\begin{array}{l}57,9 \pm \\
18,6\end{array}$ & $64,3 \pm 18,3$ & $\begin{array}{l}78,1 \pm \\
22,4\end{array}$ & $\begin{array}{l}< \\
0,0005\end{array}$ & 0,1 & $\begin{array}{l}< \\
0,0005\end{array}$ & 0,004 \\
\hline LVESV (mL) & $\begin{array}{l}23,1 \pm \\
8,8\end{array}$ & $19,8 \pm 6,7$ & $23,5 \pm 8,1$ & $\begin{array}{l}30,0 \pm \\
10,1\end{array}$ & $\begin{array}{l}<, 0005 \\
0\end{array}$ & 0,1 & $\dot{0}, 0005$ & 0,002 \\
\hline $\begin{array}{l}\text { LA volume } \\
(\mathrm{mL})\end{array}$ & $\begin{array}{l}22,3 \pm \\
7,5\end{array}$ & $19,7 \pm 6,8$ & $22,6 \pm 6,5$ & $\begin{array}{l}27,9 \pm \\
7,4\end{array}$ & 0,004 & 0,04 & $<$ & 0,002 \\
\hline $\mathrm{RA}$ area $\left(\mathrm{cm}^{2}\right)$ & $\begin{array}{l}9,1 \pm \\
2,3\end{array}$ & $8,5 \pm 2,1$ & $9,3 \pm 2,2$ & $\begin{array}{l}10,0 \pm \\
2,6\end{array}$ & 0,001 & 0,06 & 0,002 & 0,3 \\
\hline $\begin{array}{l}\text { RV basal } \\
\text { diameter (mm) }\end{array}$ & $\begin{array}{l}28,3 \pm \\
4,4\end{array}$ & $27,6 \pm 4,5$ & $28,0 \pm 3,9$ & $\begin{array}{l}30,2 \pm \\
4,2\end{array}$ & 0,001 & 0,8 & 0,001 & 0,01 \\
\hline RVOT (mm) & $\begin{array}{l}24,2 \pm \\
4,7\end{array}$ & $22,6 \pm 4,2$ & $24,6 \pm 4,2$ & $\begin{array}{l}27,1 \pm \\
4,8\end{array}$ & $\begin{array}{l}< \\
0,0005\end{array}$ & 0,02 & $<0,0005$ & 0,01 \\
\hline Aorta (mm) & $\begin{array}{l}21,6 \pm \\
3,4\end{array}$ & $20,8 \pm 3,4$ & $21,5 \pm 3,2$ & $\begin{array}{l}23,4 \pm \\
3,0\end{array}$ & $<$ & 0,4 & $\hat{0}_{0,0005}$ & 0,008 \\
\hline LVEF (\%) & $\begin{array}{l}64,2 \pm \\
4,5\end{array}$ & $65,7 \pm 3,6$ & $63,6 \pm 4,7$ & $\begin{array}{l}61,5 \pm \\
4,6\end{array}$ & $\begin{array}{l}<, 0005 \\
0,000\end{array}$ & 0,01 & $\begin{array}{l}<, 0005 \\
0,00\end{array}$ & 0,08 \\
\hline \multicolumn{9}{|c|}{$\begin{array}{l}\text { IVS: interventricular septum; LA: left atrium; LV: left ventricular; LVDD: left ventricular diastolic } \\
\text { diameter; LVEDV: left ventricular end-diastolic volume; LVESV: left ventricular end-systolic volume; } \\
\text { LVEF: left ventricular ejection fraction; LVSD: left ventricular systolic diameter; PW: posterior wall; RA: } \\
\text { right atrium; RV: right ventricle; RVOT: right ventricle outflow tract. }\end{array}$} \\
\hline \multicolumn{9}{|c|}{$\mathrm{p}^{\mathrm{a}}$ : compared normal weight and overweight groups. } \\
\hline \multicolumn{9}{|c|}{ pb: compared normal weight and obesity groups. } \\
\hline
\end{tabular}


Table 3 shows the diastolic function variables. E-wave and A-wave velocities were higher in the overweight group than in the normal weight group, and higher in obese than in overweight subjects, but the comparison did not reach statistical significance. Lateral and medial e' wave velocities were lower. Both lateral E/e' ratio and mean E/e' ratio showed significant differences $(p=0.007$ and $p=0.01$ respectively), with no significant post hoc comparison of normal weight and overweight groups in both cases. The pressure gradient between the right ventricle and right atrium was higher in the obese group $(p=0.05)$.

Table 3

Diastolic function parameters.

\begin{tabular}{|c|c|c|c|c|c|c|c|c|}
\hline & Total & $\begin{array}{l}\text { Normal } \\
\text { Weight }\end{array}$ & Overweight & Obesity & $p$ & $p^{a}$ & $p^{b}$ & $p^{c}$ \\
\hline $\begin{array}{l}\text { Peak E velocity } \\
(\mathrm{cm} / \mathrm{s})\end{array}$ & $\begin{array}{l}106,7 \pm \\
13,2\end{array}$ & $\begin{array}{l}105,5 \pm \\
13,6\end{array}$ & $\begin{array}{l}106,9 \pm \\
11,2\end{array}$ & $\begin{array}{l}109,1 \pm \\
14,4\end{array}$ & 0,3 & 0,8 & 0,3 & 0,7 \\
\hline $\begin{array}{l}\text { Peak A velocity } \\
(\mathrm{cm} / \mathrm{s})\end{array}$ & $\begin{array}{l}60,0 \pm \\
13,5\end{array}$ & $\begin{array}{l}58,3 \pm \\
13,3\end{array}$ & $59,4 \pm 12,8$ & $\begin{array}{l}64,8 \pm \\
13,8\end{array}$ & 0,2 & 0,9 & 0,02 & 0,1 \\
\hline Mitral E/A ratio & $1,9 \pm 0,4$ & $1,9 \pm 0,5$ & $1,9 \pm 0,4$ & $1,7 \pm 0,4$ & 0,1 & 0,9 & 0,1 & 0,2 \\
\hline $\begin{array}{l}\text { Peak e' lateral } \\
\text { velocity }(\mathrm{cm} / \mathrm{s})\end{array}$ & $\begin{array}{l}20,9 \pm \\
4,5\end{array}$ & $21,1 \pm 4,5$ & $21,6 \pm 4,8$ & $\begin{array}{l}19,6 \pm \\
3,6\end{array}$ & 0,06 & 0,8 & 0,09 & 0,06 \\
\hline E/e' lateral ratio & $5,3 \pm 1,2$ & $5,2 \pm 1,2$ & $5,1 \pm 2,0$ & $5,7 \pm 1,2$ & 0,007 & 0,9 & 0,02 & 0,01 \\
\hline $\begin{array}{l}\text { Peak e' medial } \\
\text { velocity }(\mathrm{cm} / \mathrm{s})\end{array}$ & $\begin{array}{l}14,1 \pm \\
2,4\end{array}$ & $14,0 \pm 2,1$ & $14,3 \pm 2,5$ & $\begin{array}{l}13,8 \pm \\
2,8\end{array}$ & 0,5 & 0,7 & 0,9 & 0,6 \\
\hline E/e' medial ratio & $7,7 \pm 1,4$ & $7,7 \pm 1,4$ & $7,6 \pm 1,4$ & $8,1 \pm 1,4$ & 0,2 & 0,9 & 0,2 & 0,3 \\
\hline $\mathrm{E} / \mathrm{e}^{\prime}$ average ratio & $6,5 \pm 1,1$ & $6,4 \pm 1,1$ & $6,3 \pm 1,0$ & $6,9 \pm 1,1$ & 0,01 & 0,9 & 0,02 & 0,02 \\
\hline $\begin{array}{l}\text { Gradient RV-RA } \\
(\mathrm{mmHg})\end{array}$ & $\begin{array}{l}16,0 \pm \\
4,7\end{array}$ & $15,8 \pm 4,9$ & $15,0 \pm 3,5$ & $\begin{array}{l}18,0 \pm \\
4,7\end{array}$ & 0,05 & 0,7 & 0,16 & 0,04 \\
\hline \multicolumn{9}{|c|}{ Gradient RV-RA: pressure gradient between right ventricle and right atrium. } \\
\hline \multicolumn{9}{|c|}{$\mathrm{p}^{\mathrm{a}}$ : compared normal weight and overweight groups. } \\
\hline \multicolumn{9}{|c|}{$\mathrm{p}^{\mathrm{b}}$ : compared normal weight and obesity groups. } \\
\hline
\end{tabular}

The association of BMI with the different echocardiographic variables was assessed by univariate regression analysis. The results are shown in table 4 . All chamber size variables assessed in the study were significant. The association was strongest for LV ventricular volumes ( $L V$ end-diastolic volume $r^{2}=$ $0.48, p<0.0005$, and LV end-systolic volume $r^{2}=0.51, p<0.0005$ ), although for all other variables the association was weaker. For diastolic function parameters the association was weak, only the right cavity pressure gradient was significant. 
Tabla 4. Univariate linear regression analysis.

\begin{tabular}{|c|c|c|c|c|c|}
\hline & $r$ & $r^{2}$ & beta & Cl 95\% & $\mathrm{p}$ \\
\hline LVDD (mm) & 0,54 & 0,29 & 0,68 & $0,54-0,83$ & $<0,0005$ \\
\hline LVSD (mm) & 0,41 & 0,17 & 0,40 & $0,28-0,51$ & $<0,0005$ \\
\hline IVS (mm) & 0,44 & 0,19 & 0,14 & $0,10-0,19$ & $<0,0005$ \\
\hline PW (mm) & 0,42 & 0,18 & 0,14 & $0,10-0,19$ & $<0,0005$ \\
\hline LV mass (g) & 0,56 & 0,32 & 4,21 & $3,37-5,05$ & $<0,0005$ \\
\hline LVEDV (mL) & 0,69 & 0,48 & 3,37 & $2,87-3,87$ & $<0,0005$ \\
\hline LVESV (mL) & 0,71 & 0,51 & 1,48 & $1,27-1,68$ & $<0,0005$ \\
\hline LA volume (mL) & 0,61 & 0,37 & 1,06 & $0,86-1,26$ & $<0,0005$ \\
\hline $\mathrm{RA}$ area $\left(\mathrm{cm}^{2}\right)$ & 0,51 & 0,26 & 0,26 & $0,20-0,32$ & $<0,0005$ \\
\hline RV basal diameter (mm) & 0,40 & 0,16 & 0,39 & $0,27-0,52$ & $<0,0005$ \\
\hline RVOT (mm) & 0,58 & 0,34 & 0,62 & $0,50-0,74$ & $<0,0005$ \\
\hline Aorta (mm) & 0,60 & 0,36 & 0,43 & $0,35-0,51$ & $<0,0005$ \\
\hline LVEF (\%) & 0,35 & 0,12 & $-0,36$ & $-0,50--0,22$ & $<0,0005$ \\
\hline E/e' lateral ratio & 0,14 & 0,02 & 0,04 & $0,00-0,07$ & 0,05 \\
\hline E/e' average ratio & 0,11 & 0,03 & 0,03 & $-0,01-0,06$ & 0,1 \\
\hline Gradient RV-RA (mmHg) & 0,21 & 0,04 & 0,26 & $0,03-0,49$ & 0,03 \\
\hline \multicolumn{6}{|c|}{$\begin{array}{l}\text { Gradient RV-RA: pressure gradient between right ventricle and right atrium, IVS: interventricular } \\
\text { septum, LA: left atrium, LV: left ventricular, LVDD: left ventricular diastolic diameter, LVEDV: left } \\
\text { ventricular end-diastolic volume, LVESV: left ventricular end-systolic volume, LVEF: left ventricular } \\
\text { ejection fraction, LVSD: left ventricular systolic diameter, PW: posterior wall, RA: right atrium, RV: right } \\
\text { ventricle, RVOT: right ventricle outflow tract. }\end{array}$} \\
\hline
\end{tabular}

Multivariate analysis was performed on those variables that were significant in the univariate analysis. The results are shown in Table 5. BMI was independently associated with all chamber size variables, as well as with LVEF, after adjusting for other baseline covariates. The best explained variables were LV mass and volumes (LV mass: $r^{2}=0.52 p<0.0005$, LV end-diastolic volume: $r^{2}=0.66 p<0.0005$, LV endsystolic volume: $\left.r^{2}=0.63 p<0.0005\right)$, aortic size $\left(r^{2}=0.56, p<0.0005\right)$ and $\operatorname{LVEF}\left(r^{2}=0.56, p<0.0005\right)$. 
Table 5

Multiple regression analysis.

\begin{tabular}{|c|c|c|c|c|c|}
\hline Dependent variables & $r^{2}$ & beta & Cl 95\% & $\mathbf{p}$ & Explanatory variables \\
\hline LVDD (mm) & 0,53 & 0,32 & $0,17-0,46$ & $<0,0005$ & IMC, edad, PAS \\
\hline LVSD (mm) & 0,32 & 0,20 & $0,07-0,32$ & 0,002 & IMC, edad \\
\hline IVS (mm) & 0,31 & 0,10 & $0,05-0,14$ & $<0,0005$ & IMC, edad, PAS, LDL \\
\hline PW (mm) & 0,24 & 0,12 & $0,07-0,17$ & $<0,0005$ & IMC, PAS, LDL, glucosa \\
\hline LV mass (g) & 0,52 & 2,31 & $1,43-3,19$ & $<0,0005$ & IMC, edad, PAS, PAD, LDL \\
\hline LVEDV (mL) & 0,66 & 2,08 & $1,61-2,55$ & $<0,0005$ & IMC, edad, PAS \\
\hline LVESV (mL) & 0,63 & 0,98 & $0,76-1,20$ & $<0,0005$ & IMC, edad, PAS, TAG \\
\hline LA volume (mL) & 0,43 & 0,89 & $0,65-1,14$ & $<0,0005$ & IMC, edad, PAS, PAD, LDL \\
\hline $\mathrm{RA}$ area $\left(\mathrm{cm}^{2}\right)$ & 0,34 & 0,18 & $0,11-0,24$ & $<0,0005$ & IMC, edad \\
\hline RV basal diameter (mm) & 0,24 & 0,28 & $0,14-0,42$ & $<0,0005$ & IMC, edad, TAG \\
\hline RVOT (mm) & 0,39 & 0,47 & $0,35-0,60$ & $<0,0005$ & IMC, edad \\
\hline Aorta (mm) & 0,56 & 0,26 & $0,19-0,33$ & $<0,0005$ & IMC, edad \\
\hline LVEF (\%) & 0,56 & $-0,36$ & $-0,50--0,22$ & $<0,0005$ & IMC \\
\hline \multicolumn{6}{|c|}{$\begin{array}{l}\text { IVS: interventricular septum; LA: left atrium; LV: left ventricular; LVDD: left ventricular diastolic } \\
\text { diameter; LVEDV: left ventricular end-diastolic volume; LVESV: left ventricular end-systolic volume; } \\
\text { LVEF: left ventricular ejection fraction; LVSD: left ventricular systolic diameter; PW: posterior wall; RA: } \\
\text { right atrium; RV: right ventricle; RVOT: right ventricle outflow tract. }\end{array}$} \\
\hline
\end{tabular}

\section{Discussion}

The main findings of this study are that the percentage of overweight and obesity in children and adolescents in our population is high compared to previous studies, and that overweight and obesity in children and adolescents is independently and negatively associated with cardiac morphology and function parameters measured by echocardiography.

In the study by Sánchez-Cruz et al. [17] the prevalence of childhood overweight is $26 \%$ and that of childhood obesity is $12.6 \%$. Data from the recently published ENPE study show a prevalence of childhood obesity of $10.3 \%$ [1]. The percentage of overweight in our sample was $26.9 \%$ and the percentage of obesity was $23.1 \%$, higher than that reported in previous population-based studies in Spain. These findings could be correlated with a heterogeneous distribution of obesity in the different areas of our country. The enKid study [18], designed to assess the dietary and nutritional habits of children and young people, reported that the Canary Islands and Andalusia had the highest rates of childhood obesity. These data are consistent with the high rates of overweight and obesity in our study. 
Furthermore, the results of our study show that higher BMI in childhood is independently associated with increased ventricular wall thickness and LV mass, as well as with increased LV size in both diastolic and systolic volumes. Similarly, higher BMI is associated with increased size of both atria, right ventricle and ascending thoracic aorta. Regarding LV systolic function, the overweight and obese groups of children and adolescents had a lower ejection fraction compared to the normal weight group, and increased BMI was independently associated with decreased LVEF with acceptable goodness-of-fit.

Previous studies have described a relationship between childhood obesity and increased left ventricular mass and altered diastolic parameters. The group of Saltijeral et al [11], describes an increase in LV size and LV wall thickness in the childhood obesity group compared to the control group. Mangner et al [12] describe LV and left atrial enlargement and worse diastolic function in obese children and adolescents. Dias et al [13], agree with previous studies in that adolescents with obesity showed an increase in left ventricular thickness and size. In this respect, our results are in line with those of previous studies published on this topic.

However, these previous studies were case-control studies with small samples, and only the study by Saltijeral et al. was conducted in our setting. In this respect, our study provides relevant information from a large, randomly selected sample of a rural Spanish child population. Furthermore, none of these studies reported a significant worsening of LVEF in the obese group, nor an independent relationship of BMI with worsening LVEF.

Based on our results, in childhood obesity we observed an adaptation of the LV by dilation and hypertrophy, in a similar way that is reported in adult obesity, and it may be related to the increase in cardiac output needed to meet the metabolic demands. Our group is concerned about the high prevalence of childhood overweight and obesity, as well as the structural and functional changes observed in the cardiac cavities of overweight and obese children and adolescents, leading to an increased cardiac chamber size and an impaired LV systolic and diastolic function. Although these structural and functional changes are far from clinical significance, it is likely that these changes, present an early age, may persist over time, and should be considered as incipient changes for the development of obesity cardiomyopathy in adulthood.

It has been described that therapeutic intervention on obesity in adulthood and the reduction of BMI is accompanied by significant structural improvements, even reaching complete normalisation of the cardiac structure [19]. Extrapolating this information to children, this research group considers that therapeutic intervention on childhood obesity would set a great precedent in the primary prevention of cardiovascular events in this population risk group.

As a main limitation of the study, our group considers that, being designed as a cross-sectional study, it does not really allow us to assess whether these structural changes can be maintained over time into adulthood. Similarly, it does not allow us to assess whether an intervention on obesity in childhood could reverse the structural and functional changes observed. Further sample follow-up or obesity intervention studies would be needed to answer these questions. On the other hand, it is a study carried out in a 
specific population in southern Spain and may be the results, at least in terms of prevalence of childhood obesity, may not be extrapolated to other regions.

\section{Conclusion}

The result of this study shows that obesity in childhood is independently associated with significant changes in the structure and function of the different cardiac chambers. These changes are associated with unfavourable alterations early in life.

\section{Abbreviations}

BMl: body mass index

LV: left ventricular

LVEF: left ventricular ejection fraction

\section{Declarations}

\section{Acknowledgments}

We would like to thank Sara Perote Lázaro for her expert and dedicated collaboration in the style and grammar correction of this article.

\section{References}

1. Aranceta-Bartrina J, Gianzo-Citores M, Pérez-Rodrigo C (2020) Prevalence of overweight, obesity and abdominal obesity in the Spanish population aged 3 to 24 years. The ENPE study. Rev Esp Cardiol 73:290-299

2. Ng M, Fleming T, Robinson $\mathrm{M}$ et al (2014) Global, regional, and national prevalence of overweight and obesity in children and adults during 1980-2013: a systematic analysis for the Global Burden of Disease Study 2013. Lancet 384:766-781

3. Ebbeling CB, Pawlak DB, Ludwig DS (2002) Childhood obesity: public-health crisis, common sense cure. Lancet 360:472-482

4. Umer A, Kelley GA, Cottrell LE et al (2017) Childhood obesity and adult cardiovascular disease risk factors: a systematic review with meta-analysis. BMC Public Health 17:683

5. Reilly JJ, Kelly J (2011) Long-term impact of overweight and obesity in childhood and adolescence on morbidity and premature mortality in adulthood: systematic review). Int J Obes 35:891-898

6. López-Jímenez F, Cortés-Bergoderi M (2011) Obesity and the heart. Rev Esp Cardiol 64:140-149

7. Kasper EK, Hruban RH, Baughman KL (1992) Cardiomyopathy of obesity: a clinicopathologic evaluation of 43 obese patients with heart failure. Am J Cardiol 70:921-924 
8. lacobellis G, Ribaudo MC, Zappaterreno A et al (2004) Adapted changes in left ventricular structure and function in severe uncomplicated obesity. Obes Res 12:1616-1621

9. Alpert MA, Chan EJ (2012) Left ventricular morphology and diastolic function in severe obesity: current views. Rev Esp Cardiol 65:1-3

10. Rider OJ, Lewis AJ, Neubauer S (2014) Structural and metabolic effects of obesity on the myocardium and the aorta. Obes Facts 7:329-328

11. Saltijeral A, Pérez de Isla L, Pérez-Rodríguez $O$ et al (2011) Early myocardial deformation changes associated to isolated obesity: a study based on 3D-wall motion tracking analysis. Obesity 19:22682273

12. Mangner N, Scheuermann K, Winzer E et al (2014) Childhood obesity. Impact on cardiac geometry and function. JACC Cardiovasc Imaging 7:1198-1205

13. Dias KA, Spence AK, Sarma S et al (2017) Left ventricular morphology and function in adolescents: relations to fitness and fatness. Int J Cardiol 240:313-319

14. De Onis M, Onyango AW, Borghi E et al (2007) Development of a WHO growth reference for schoolaged children and adolescents. Bull World Health Organ 85:660-667

15. Devereux RB, Alonso DR, Lutas EM et al (1986) Echocardiographic assesment of left ventricular hypertrophy: comparison to necropsy findings. Am J Cardiol 57:450-458

16. Lopez L, Colan SD, Frommelt PC et al (2010) Recommendations for quantification methods during the performance of a pediatric echocardiogram: a report from the pediatric measurements writing group of the American Society of Echocardiography Pediatric and Congenital Heart Disease Council. J Am Soc Echocardiogr 23:465-495

17. Sánchez-Cruz JJ, Jímenez-Moleón JJ, Fernández-Quesada F et al (2013) Prevalence of child and youth obesity in Spain in 2012. Rev Esp Cardiol 66:371-376

18. Serra Majem L, Ribas Barba L, Aranceta Bartrina J et al (2003) Childhood and adolescent obesity in Spain. Results of the enKid study (1998-2000). Med Clin 121:725-732

19. Luances M, Cachofeiro V, García-Muñoz-Najar A et al (2012) Anatomical and functional alterations of the heart in morbid obesity. Rev Esp Cardiol 65:14-21 